\title{
Relationship Between Serum Vitamin D Level and the Presence of Allergies in a Pediatric Population: A Case Study
}

\author{
Jay Vithalani ${ }^{\mathrm{a}, \mathrm{c}}$, Pamraj Sharma ${ }^{\mathrm{a}}$, Runette Flowers ${ }^{\mathrm{b}}$
}

\begin{abstract}
Background: Vitamin D plays an important immunological role in the body and a deficiency of vitamin $\mathrm{D}$ is suggested to be linked to the incidence of allergies in childhood. The aim of this study was to investigate the relationship between allergies and vitamin D levels in this given pediatric population.
\end{abstract}

Methods: A case study using 105 children from Decatur, Georgia was done to assess the relationship between childhood allergies and serum vitamin D levels.

Results: Vitamin D levels were assessed and grouped as deficient, insufficient or sufficient. There is a relationship between children who suffer from allergies and also display low levels of vitamin D.

Conclusion: Findings from this study suggest that there is a possible relationship between presence of allergies and low levels of serum vitamin D.

Keywords: Vitamin D; Allergies; Immunology; Pediatrics; Immunomodulatory; Atopy

\section{Introduction}

Seasonal allergies are among the most common chronic medical conditions in the world. In the United States alone, approximately 50 million people are affected. It is estimated that approximately 17 million adults and upwards of 7 million

\footnotetext{
Manuscript accepted for publication June 24, 2016

${ }^{a}$ Clinical Science Department, American University of Antigua College of Medicine, One Battery Park Plaza, 33rd Floor, New York, NY 10004, USA

${ }^{\mathrm{b}}$ Clinical Science Department, Faculty of Pediatrics, American University of Antigua College of Medicine, One Battery Park Plaza, 33rd Floor, New York, NY 10004, USA

${ }^{\mathrm{c} C o r r e s p o n d i n g ~ A u t h o r: ~ J a y ~ V i t h a l a n i, ~ A m e r i c a n ~ U n i v e r s i t y ~ o f ~ A n t i g u a ~ C o l-~}$ lege of Medicine 630 Main Street, Brawley, CA 92227, USA.

Email: jayv@auamed.net
}

doi: http://dx.doi.org/10.14740/ijcp251w children suffer from allergy-related conditions [1]. Allergies contribute to a significant social and financial burden on public health. When considered economically, this is associated with a direct annual loss of 18 billion dollars and an indirect loss of almost 4 million days of work and school time [1].

Seasonal allergies are generally caused by a variety of environmental substances, such as pollens and dust. These particles set off immune reactions that can cause a variety of symptoms varying in presentation and intensity depending on time of day or the season. In pediatric populations, these allergy symptoms can range from just making a child feel miserable to putting them at risk for life-threatening conditions. These symptoms can not only interfere with their sleep and limit their activities, but can also interfere with their education [1]. Because of the array of different presentations of allergic symptoms, at times allergies are confused with other medical conditions leading to mis-diagnoses and furthermore, mistreatment of patients.

Seasonal allergies are a type of chronic respiratory condition that is characterized by inflammation of the upper airway tract. This inflammation is mediated by enhanced activity of mast cells, basophils and TH2 cells which induce IgE and histamine production, leading to inflammation and dilating mucosal capillaries. By dilating mucosal capillaries, IgE and histamine allow for goblet cells to become hyper responsive and thus, produce more mucus. This produces symptoms seen in allergic reactions.

Causes of allergic reactions are relatively unknown but several dietary deficiency proposals have been made. Among them, the suggestion that decreased serum concentrations of 1-25 dihydroxycholecalciferol, or vitamin D3, is of particular interest. Vitamin D3 deficiency is common in the United States. Research has suggested that low vitamin D levels are associated with urban and Western lifestyles, specifically decreased amount of time spent outdoors, decreased levels of physical activity and an overall decrease in exposure to sunlight [2]. Deficiency of vitamin D can also be associated with increased rates of lactose intolerance and sensitivity leading to decreased ingestion of milk and milk products, decreasing the amount of vitamin D available in the body.

Several studies have confirmed the association between vitamin D deficiency and the likelihood of allergy development. Vitamin D is known to play a pivotal role in calcium regulation, bone growth and bone regulation. Some studies 
Table 1. Comparison of Serum Vitamin D Levels in Children With Known Allergies

\begin{tabular}{ll}
\hline Vitamin D levels & Children with allergies \\
\hline Deficient $(<20 \mathrm{ng} / \mathrm{mL})$ & $47(45 \%)$ \\
Insufficient $(20-30 \mathrm{ng} / \mathrm{mL})$ & $40(38 \%)$ \\
Sufficient $(>30 \mathrm{ng} / \mathrm{mL})$ & $18(17 \%)$ \\
\hline
\end{tabular}

also suggest that vitamin D has immunoprotective properties as well $[3,4]$. Vitamin D has been shown to play an important role in modulating immune responses from epithelial cells, B lymphocytes, antigen presenting cells and T lymphocytes [3]. Most recent studies also confirm its effect on T regulatory cells, which are specialized T lymphocytes that are known to regulate the immune response by production of IL10, an inhibitory cytokine. This allows T regulatory cells to interrupt T-cell response and modulate inflammation. The study by Maalmi et al suggests that decreases in vitamin D levels can lead to immune system malfunction and increased incidence of respiratory problems and bronchial inflammation $[4,5]$.

The aim of this study was to establish a positive relationship between vitamin D deficiency and allergy prevalence in a pediatric population living in the southeast part of Decatur, a suburb of Atlanta, Georgia, USA using a case study design.

\section{Subjects and Methods}

This investigation was performed at a pediatric clinic under the care of Dr. Runette Flowers, an affiliate with the American University of Antigua College of Medicine. One hundred five children aged 6 - 20 years were selected for this study. Children who were known to have chronic respiratory conditions that were not allergy-related were excluded from this study. Children who were currently taking vitamin supplements or had a history of vitamin D intake were also excluded from this study.

Blood samples were collected from the subjects by venipuncture. Once collected, these samples were sent to local licensed laboratories to be analyzed and tested for levels of vitamin D. Values obtained for vitamin D were categorized into three categories depending on the level present as determined by the Endocrine Society: levels greater than $30 \mathrm{ng} / \mathrm{mL}$ were considered as sufficient, between 20 and $30 \mathrm{ng} / \mathrm{mL}$ as insufficient and lower than $20 \mathrm{ng} / \mathrm{mL}$ as deficient [6].

\section{Results}

This study evaluated 105 children aged 6 - 20 years, 64 male and 41 female, with known allergies for vitamin D deficiency. The demographic data of children with allergies and vitamin D level are shown in Table 1. Out of all 105 children evaluated, decreased vitamin $\mathrm{D}(<30 \mathrm{ng} / \mathrm{mL})$ was present in 87 children (83\%). Forty-five percent of these children can be classified as deficient $(<20 \mathrm{ng} / \mathrm{mL})$, while $38 \%$ are classified as insufficient $(>20 \mathrm{ng} / \mathrm{mL}$ but $<30 \mathrm{ng} / \mathrm{mL})$. Eighteen of the children who presented with allergies had normal vitamin D levels $(17 \%)$ (Table 1).

\section{Discussion}

In this clinical population, there appears to be a clear association between presence of decreased vitamin D levels in children suffering from allergies. This is in agreement with the study published by Hollams et al [7] that stated that children with allergies consistently presented with a vitamin $\mathrm{D}$ deficiency. Bener et al [8] suggest that there is a link between early vitamin $\mathrm{D}$ deficiency in children and the development of respiratory problems later on since vitamin D is involved in several immunological processes.

One possible reason for presence of low vitamin D levels in these children could be that children with allergies tend to spend less time outdoors, which in turn results in a lower exposure to sunshine [9]. This is especially true with the convenience of electronics and television in today's age where children are less inclined to go outdoors.

Vitamin D has been thought to be involved in immunemodulatory pathways of some cells. Research has suggested that vitamin D helps to reduce Th2 cell activity. Th2 cells produce IL4, which is a direct downregulator of the vitamin D receptor [4]. This results in the heightened inflammation in the airway and the weakening of the immunological defense mechanisms of the body against infections and inflammation [9]. Studies have also shown that vitamin D also enhances the production of IL10, an anti-inflammatory cytokine from B and T lymphocytes [4]. This study, combined with the results of other studies, shows that vitamin D may also play a role in regulation of signaling pathways in cells that work to limit hyper-responsiveness of the inflammatory cells, so that they do not produce a hypertrophic response [2].

There are several limitations present in this study. The first is the sample size. Although clear evidence can be seen to support that children with allergies tend to have low levels of vitamin $\mathrm{D}$, a larger population can help solidify the relationship further. Second limitation is that there is no control group in this study. It would be favorable to have a control group, so that statistical tests can be evaluated to ensure accuracy of data.

\section{Conclusion}

This study demonstrates the presence of decreased vitamin $\mathrm{D}$ levels in this pediatric population suffering from allergies. Therefore, we suggest that children be tested for serum vitamin D levels if they suffer from allergies or its associated conditions such as asthma and atopic dermatitis. The corrected level of vitamin D can help in reducing severity of allergy symptoms, most likely by reducing the production of $\mathrm{IgE}$ and/or eosinophil count and regulating T-cell functions. Along with reducing the symptoms, normal levels of vitamin D can ensure healthy development of bones in a growing pediatric population. Children who are found to have low levels of vitamin $\mathrm{D}$ should be 
supplemented as per guidelines. Further studies should also be done to demonstrate the efficacy of corrected vitamin D level to alleviate allergy symptoms. A study performed in general population with broader age range may also solidify the role vitamin D plays in producing allergy symptoms.

\section{Acknowledgments}

We would like to give special thanks to Dr. Alvin Eden, MD, Clinical Chair, Pediatrics, American University of Antigua College of Medicine.

\section{Disclosure}

The authors have nothing to disclose.

\section{References}

1. Allergy Facts. American College of Allergy, Asthma and Immunology, 18 Feb 2016. Web. March 2016. <http:// acaai.org/news/facts-statistics/allergies>.

2. Dogru M, Kirmizibekmez H, Yesiltepe Mutlu RG, Aktas A, Ozturkmen S. Clinical effects of vitamin D in children with asthma. Int Arch Allergy Immunol. 2014;164(4):319325 .
3. Hatami G, Ghasemi K, Motamed N, Firoozbakht S, Movahed A, Farrokhi S. Relationship between Vitamin D and Childhood Asthma: A Case-Control Study. Iran J Pediatr. 2014;24(6):710-714.

4. Maalmi H, Berraies A, Tangour E, Ammar J, Abid H, Hamzaoui K, Hamzaoui A. The impact of vitamin D deficiency on immune $\mathrm{T}$ cells in asthmatic children: a casecontrol study. J Asthma Allergy. 2012;5:11-19.

5. Searing DA, Leung DY. Vitamin D in atopic dermatitis, asthma and allergic diseases. Immunol Allergy Clin North Am. 2010;30(3):397-409.

6. Holick MF, Binkley NC, Bischoff-Ferrari HA, Gordon CM, Hanley DA, Heaney RP, Murad MH, et al. Evaluation, treatment, and prevention of vitamin $\mathrm{D}$ deficiency: an Endocrine Society clinical practice guideline. J Clin Endocrinol Metab. 2011;96(7):1911-1930.

7. Hollams EM, Hart PH, Holt BJ, Serralha M, Parsons F, de Klerk NH, Zhang G, et al. Vitamin D and atopy and asthma phenotypes in children: a longitudinal cohort study. Eur Respir J. 2011;38(6):1320-1327.

8. Bener A, Ehlayel MS, Tulic MK, Hamid Q. Vitamin D deficiency as a strong predictor of asthma in children. Int Arch Allergy Immunol. 2012;157(2):168-175.

9. Checkley W, Robinson CL, Baumann LM, Hansel NN, Romero KM, Pollard SL, Wise RA, et al. 25-hydroxy vitamin D levels are associated with childhood asthma in a population-based study in Peru. Clin Exp Allergy. 2015;45(1):273-282. 